\title{
Reducing cardiovascular risk caused by air pollution: individuals can make a difference
}

\author{
Elliot N. Mahlof ${ }^{1} \cdot$ John D. Bisognano $\mathbb{B}^{1}$
}

Received: 23 July 2020 / Revised: 3 August 2020 / Accepted: 12 August 2020 / Published online: 1 September 2020

(c) Springer Nature Limited 2020

Cardiovascular disease (CVD) remains the leading cause of global mortality, accounting for nearly one-third of all deaths. Over $70 \%$ of CVD cases can be attributed to a small cluster of modifiable risk factors. In a prospective study of 155,722 participants, metabolic factors were the predominant risk factor for developing CVD, with hypertension being the most significant. While more than half of all cardiovascular events can be attributed to high blood pressure (BP), hypertension remains largely undertreated [1]. There are 103 million adults in the United States with hypertension, but less than half are currently treated to goal.

Black patients are two to three times more likely to die of a preventable cardiovascular disease than white patients, so addressing these social disparities is of great importance [2]. The long-standing management paradigm has focused on identifying patient-level risk factors and treating each person individually. Both lifestyle modification and use of medications can effectively lower BP, but the excess burden of hypertension among blacks has also been driven by medication nonadherence. There is also an under-appreciation of masked hypertension among this population [3]. Health policies should naturally focus on approaches that improve adherence and more effectively identify masked hypertension. Identifying novel approaches to risk factor management may also have a role in combating these health disparities [4].

There is growing evidence that environmental exposures have a profound effect on BP [5, 6]. Fine particulate matter $<2.5 \mu \mathrm{m}$ (PM2.5) air pollution is a CV risk factor [7] that accounts for 8.9 million deaths per year and disproportionately affects low wealth communities and communities of color [8].

$\triangle$ John D. Bisognano

John_Bisognano@urmc.rochester.edu

1 University of Rochester Medical Center, Department of Internal Medicine, Cardiology Division, 601 Elmwood Avenue, Box 679, Rochester, NY 14642, USA
In the US, exposure to air pollution is strikingly different by race and ethnicity due to racial segregation in housing. Acute exposure to PM2.5 can raise BP, whereas chronic exposure can promote development of overt hypertension. On the other hand, reducing exposure to PM2.5 has been shown to decrease BP within a few days.

The burden that air pollution has on morbidity and mortality is significant, but are there practical opportunities to reduce these exposures in a clinically meaningful way? At the population-level, regulations that lower emissions have been shown to directly improve public health outcomes. However, population-level interventions that require societal-level interventions are historically not addressed with cost often cited as a barrier, not to mention a relatively long period of time to see return on investment. While clinicians and healthcare organizations should certainly advocate for clean air policies whenever possible to help protect their patients and the environment, this societal approach has practical limitations that has historically slowed widespread participation [9].

At the individual-level, several interventions have also been shown to be at least partially effective in reducing PM2.5 exposures. In this issue of the Journal of Human Hypertension, Newman et al review the current evidence that reducing PM2.5 lowers BP and aim to demonstrate how individual-level strategies to reduce air pollution exposure may be a novel approach to managing hypertension. One promising and relatively inexpensive method is the use of portable indoor air purifiers (PACs), which can lower PM2.5 levels by $>50 \%$. In a meta-analysis of 10 studies ( $n=604)$ using portable air cleaners (PACs) over the short term (mean 13.5 days), PACs were shown to consistently lower indoor PM2.5 levels. On average, the use of PACs decreased systolic BP by $3.9 \mathrm{mmHg}$. These effects were consistent across all ages, locations, and durations. PACs also lowered BP regardless of the baseline PM2.5 level, which indicates that $\mathrm{BP}$ can be significantly improved without needing to achieve some lower absolute threshold of PM2.5. 
Since many vulnerable populations suffer from poor air quality and have inadequate BP control, PACs seem to be a well-positioned intervention to improve global public health and address health disparities at a low cost with no notable risk [10]. Newman et al. give a call to action and remind us of the importance of reversible and manageable environmental factors that can lead to improved cardiovascular health. While this news is encouraging, there have been no randomized clinical studies to conclusively support the use of these personalized interventions. Neither the American Heart Association nor the European Society of Cardiology provide formal recommendations regarding their use, but suggest that patients and healthcare providers may take individual actions to reduce or prevent the adverse effects of air pollution.

During the COVID-19 pandemic, many health care providers have adopted televideo and phone visits out of necessity, but this necessity has given us an opportunity to learn. While such visits cannot always take the place of inperson visits, many patients can be adequately managed remotely. Anecdotally, these visits lowered our no-show rate and improved access to patients with transportation issues, limited mobility, and those traveling long distances to see providers sometimes in inclement weather. In addition to maximizing patient access, there may be a positive environmental impact from these remote visits. If just one gallon of gasoline is saved with each video visit (a conservative estimate), 20 pounds of carbon dioxide is not produced. If just four patients per day are seen by video rather than in person, that can be nearly ten tons of $\mathrm{CO} 2$ not placed in the environment annually. Imagine the potential over an entire practice or health system! As we look more toward environmental pollution as a driver of cardiovascular risk, televideo may be one the most important tools in our armamentarium-but in the meantime, PAC's as described by Newman et al. in this issue may be an important good start.

\section{Compliance with ethical standards}

Conflict of interest The authors declare that they have no conflict of interest.
Publisher's note Springer Nature remains neutral with regard to jurisdictional claims in published maps and institutional affiliations.

\section{References}

1. Dagenais GR, Leong DP, Rangarajan S, Lanas F, Lopez-Jaramillo P, Gupta R, et al. Variations in common diseases, hospital admissions, and deaths in middle-aged adults in 21 countries from five continents (PURE): a prospective cohort study. Lancet. 2020;395:785-94. https://doi.org/10.1016/S0140-6736(19)32007-0.

2. Ferdinand KC, Yadav K, Nasser SA, Clayton-Jeter HD, Lewin J, Cryer DR, et al. Disparities in hypertension and cardiovascular disease in blacks: The critical role of medication adherence. J Clin Hypertens (Greenwich). 2017;19:1015-24. https://doi.org/10. 1111/jch.13089. Epub 2017 Aug 30.

3. Booth JN 3rd, Diaz KM, Seals SR, Sims M, Ravenell J, Muntner P, et al. Masked hypertension and cardiovascular disease events in a prospective cohort of blacks: the jackson heart study. Hypertension. 2016;68:501-10. https://doi.org/10.1161/HYPERTENSIONAHA. 116.07553. Epub 2016 Jun 27.

4. Musemwa N, Gadegbeku CA. Hypertension in African Americans. Curr Cardiol Rep. 2017;19:129 https://doi.org/10.1007/s11886-0170933-z. Published 2017 Oct 28.

5. Rajagopalan S, Al-Kindi SG, Brook RD. Air pollution and cardiovascular disease: JACC state-of-the-art review. J Am Coll Cardiol. 2018;72:2054-70. https://doi.org/10.1016/j.jacc.2018.07. 099.

6. Sharma P, Brook RD. Echoes from Gaea, Poseidon, Hephaestus, and Prometheus: environmental risk factors for high blood pressure. J Hum Hypertens. 2018;32:594-607. https://doi.org/10. 1038/s41371-018-0078-6.

7. Brook RD, Newby DE, Rajagopalan S. Air pollution and cardiometabolic disease: an update and call for clinical trials. Am J Hypertens. 2017;31:1-10. https://doi.org/10.1093/ajh/ hpx 109 .

8. Sripipatana A, Pourat N, Chen X, Zhou W, Lu C. Exploring racial/ethnic disparities in hypertension care among patients served by health centers in the United States. J Clin Hypertens (Greenwich). 2019;21:489-98. https://doi.org/10.1111/jch.13504.

9. Brook RD, Kousha T. Air pollution and emergency department visits for hypertension in edmonton and calgary, canada: a casecrossover study. Am J Hypertens. 2015;28:1121-6. https://doi.org/ 10.1093/ajh/hpu302.

10. Tibuakuu M, Michos ED, Navas-Acien A, Jones MR. Air pollution and cardiovascular disease: a focus on vulnerable populations worldwide. Curr Epidemiol Rep. 2018;5:370-8. https://doi.org/10. 1007/s40471-018-0166-8. 